\title{
Growth mechanism of planar or nanorod structured tungsten oxide thin films deposited via aerosol assisted chemical vapour deposition (AACVD)
}

\author{
Min Ling ${ }^{1}$, Chris Blackman ${ }^{*}, 1$ \\ ${ }^{1}$ Department of Chemistry, University College London, 20 Gordon Street, London WC1H 0AJ, UK
}

Received ZZZ, revised ZZZ, accepted ZZZ

Published online ZZZ (Dates will be provided by the publisher.)

Keywords growth mechanism, aerosol assisted chemical vapour deposition (AACVD), nanorod, tungsten oxide.

* Corresponding author: e-mail c.blackman@ucl.ac.uk, Phone: +44 207679 4703, Fax: +44 2076794703

\begin{abstract}
Aerosol assisted chemical vapour deposition (AACVD) is used to deposit tungsten oxide thin films from tungsten hexacarbonyl $\left(\mathrm{W}(\mathrm{CO})_{6}\right)$ at 339 to $358{ }^{\circ} \mathrm{C}$ on quartz substrate. The morphologies of as-deposited thin films, which are comprised of two phases $\left(\mathrm{W}_{25} \mathrm{O}_{73}\right.$ and $\left.\mathrm{W}_{17} \mathrm{O}_{47}\right)$, vary from planar to nanorod (NR) structures as the distance from the inlet towards the outlet of the reactor is traveresed. This is related to variation of the actual temperature on the substrate surface $\left(\Delta T=19^{\circ} \mathrm{C}\right)$, which results in a change in growth mode due to competition between growth rate (perpendicular to substrate) and nucleation rate (parallel to substrate). When the ratio of perpendicular growth rate to growth rate contributed by nucleation is higher than 7.1, the as-deposited tungsten oxide thin film forms as NR.
\end{abstract}

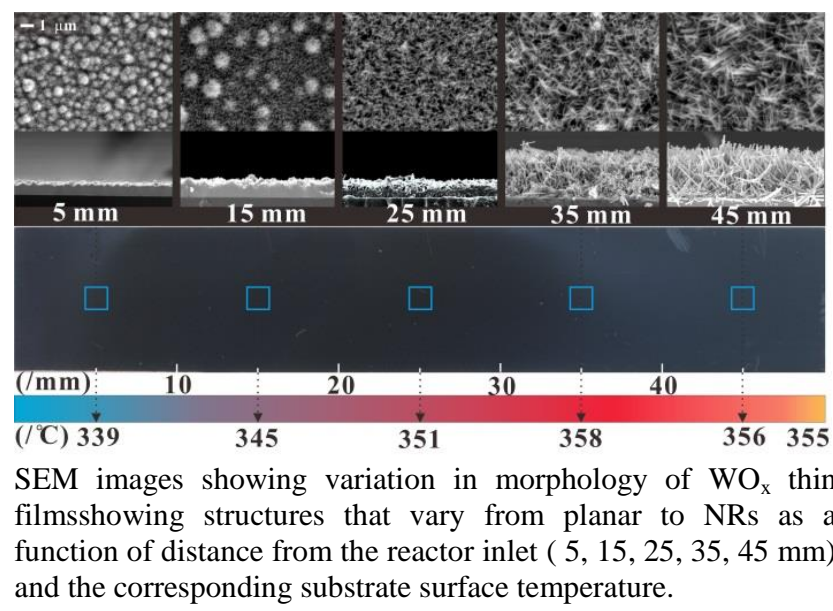

Copyright line will be provided by the publisher

1 Introduction Tungsten oxides have attracted extensive interest due to their multi-functional properties in electrochromic [1,2], catalytic [3], photocatalytic [4], gassensing [5,6], water splitting [7] and photovoltaic [8] applications. Tungsten oxide thin films with various morphologies, including three dimensional (3D) ball-like, 2D planar and 1D nanorod (NR) structures have shown different electrochromic photochemical, optical, photocatlysis and gas sensing properties [9-11].

Aerosol assisted chemical vapour deposition (AACVD) is as a variant of the conventional CVD process which uses solvent aerosols to transport precursors, which can therefore have relatively low volatilities as long as they are soluble [12]. Tungsten oxide thin films with planar or
NR structure have been previously deposited by AACVD [13-15].

In order to design and control tungsten oxide thin film growth, an understanding of the growth mechanism is important. In general, deposition of thin films usually proceeds via nucleation and growth stages which include three modes: Frank van-der-Merwe (FM) (layer-by-layer), Stranski-Krastanov (SK) (layer plus island) and VolmerWeber (VM) (island) [16]. For synthesis of 1D tungsten oxide NR structures, both vapour-solid (VS) and vapourliquid-solid (VLS) growth mechanisms have been reported $[17,18]$. Recently, a planar defect driven growth mechanism was proposed in which oxygen defects parallel to the NR growth direction [010] compress the growth direction 
along the [100] and [001] directions resulting in anisotropic growth [19].

We have deposited tungsten oxide thin films via AACVD using tungsten hexacarbonyl $\mathrm{W}(\mathrm{CO})_{6}$. In our reactor the actual substrate temperature on the surface changes from 339 to $358{ }^{\circ} \mathrm{C}$ traversing from the inlet to the outlet of the reactor, and the morphology of the tungsten oxide thin film formed transitions from planar to NR. Herein, we analysed every $5 \mathrm{~mm}$ of as-synthesized thin films between 5 and $45 \mathrm{~mm}$ from the inlet of the reactor (total reactor length $=60 \mathrm{~mm}$ ). We consider the morphology change due to the competition between nucleation and perpendicular growth for tungsten adatoms and calculate the simulated atomic processes of tungsten oxide thin film growth by combining kinetic factors and statistical mechanical arguments. Hence we relate the change of substrate temperature and the molar concentration of precursor in the vapour to changes in nucleation rate and perpendicular growth rate, resulting in the change from planar to NR structure. We find that when the ratios of perpendicular growth rate to growth rate contributed by nucleation increase the structure transitions from planar to NR, e.g. below 7.1 a planar structure is favoured and above 7.1 a NR structure is favoured.

\section{Experimental}

2.1 Synthesis of tungsten oxide thin film via AACVD The precursor W(CO) 6 (99\%, Aldrich ) $(0.060 \mathrm{~g})$ was dissolved in 2:1 a mixture of acetone (99\%, Emplura) and methanol (99.5\%, Emplura) (15 $\mathrm{cm}^{3}$ total volume). Aerosols of the solution were generated using an ultrasonic humidifier (Liquifog, Johnson Matthey operating at 2 $\mathrm{MHz}$ ) and transported to the reactor using nitrogen carrier gas $(99.99 \%$, BOC, flow rate $300 \mathrm{sccm})$ controlled by a mass flow controller (MFC, Brooks). After $30 \mathrm{~min}$ deposition at a set temperature of $350{ }^{\circ} \mathrm{C}$ on a quartz substrate, the heater and humidifier were switched off to stop deposition and the reactor naturally cooled under $\mathrm{N}_{2}$ to room temperature. The schematic diagram of the AACVD system used is presented in Figure 1. The inlet to the cold wall reactor is equipped with a water jacket to avoid precursor heating and decomposition prior to entering the reactor chamber. The exhaust was directly vented into the extraction system of the fume cupboard.

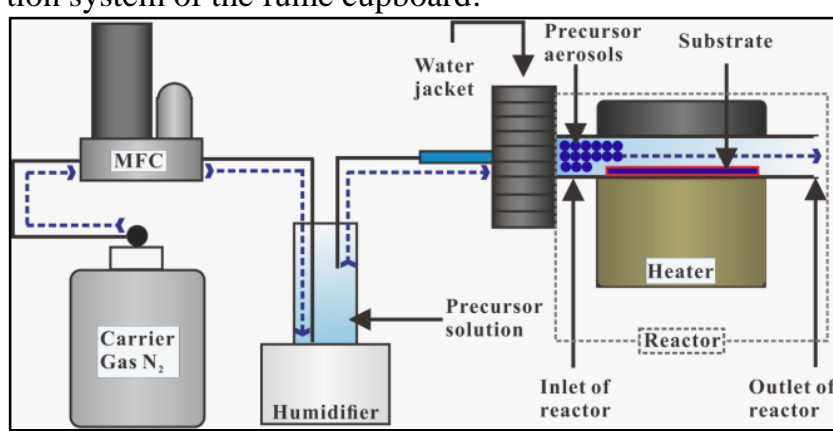

Figure 1 Schematic flow diagram of the AACVD reactor.
2.2 Characterization The actual temperature of the substrate was determined at 5, 15, 25, 35 and $45 \mathrm{~mm}$ along the quartz by a type-k thermocouple which was stuck to the surface using copper metal tape, and the temperature recorded by a temperature controller (EUROTHEM 2116). It is acknowledged that this setup is unlikely to provide the absolute temperature and therefore all our results are relative. Scanning Electron Microscopy (SEM) images were obtained on a JEOL 6301F. Samples were coated with gold and scanned at $5 \mathrm{kV}$. X-Ray diffraction (XRD) patterns were acquired by a Bruker D8-Discover reflection diffractometer equipped with a LinxEye silicon strip detector using $\mathrm{Cu} \mathrm{K \alpha}$ radiation operated at $40 \mathrm{kV}$ and $40 \mathrm{~mA}$. The $\mathrm{X}-$ ray photoelectron (XPS) analysis was carried on a Thermo Scientific K-Alpha instrument equipped with a monochromatic Al $\mathrm{K} \alpha$ radiation $(1486.6 \mathrm{eV})$ with charge compensation by a beam charge neutralization argon-ion gun $(\leq 10 \mathrm{eV})$, and calibrated by the $\mathrm{C} 1 \mathrm{~s}$ peak at $284.8 \mathrm{eV}$. Transmission electron microscopy (TEM) and scanning TEM (STEM) analysis was performed on a JEOL 2100 at $300 \mathrm{KV}$ equipped with energy dispersion X-ray (EDX) detetor (X-MaxN 80, Oxford Instruments).

\section{Results and discussion}

3.1 Characterization of tungsten oxide thin

films Films deposited on quartz substrates for $30 \mathrm{~min}$ at 339 to $358{ }^{\circ} \mathrm{C}$ appeared blue in colour as shown in Figure 2 . The NR structure we have observed previously [14] was found at a distance between 25 and $50 \mathrm{~mm}$ from the inlet of the reactor, where the temperature was recorded between 351 to $358{ }^{\circ} \mathrm{C}$ on the surface of a quartz substrate. A dense planar structure appeared within the first $25 \mathrm{~mm}$ of the thin film, where the temperature was below $351{ }^{\circ} \mathrm{C}$ on the surface of substrate, as demonstrated in Figure 2. The blue colour was darker at the front of substrate, but the mean thickness of thin film increased at $5(762 \pm 100), 15$ $(1116 \pm 400), 25(1520 \pm 200), 35(3834 \pm 300)$ and 45 $\mathrm{mm}(4004 \pm 500 \mathrm{~nm})$ from the inlet, as shown in SEM images in Figure 2. This apparent contradiction between optical colour and apparent film thickness is likely due to formation of the more dense planar structure near the inlet and the less dense NR structure further from the inlet, where we estimate the NR's at 35 and $45 \mathrm{~mm}$ occupy only 50 and $38 \%$ of the substrate area respectively (estimated by counting the areas of white (NRs) and black pixels (gaps) from SEM images in Figure 2).

Glancing angle $\mathrm{X}$-ray diffraction shows two relative intense peaks at 23.48 and $48.02^{\circ}(2 \theta)$ on all points within the thin film, as shown in Figure 3. These two peaks can be attributed to the (010) and (020) reflections of the monoclinic $\mathrm{W}_{17} \mathrm{O}_{47}\left(\mathrm{WO}_{2.77}\right)$ structure (ICSD 01-079-0171, $\mathrm{P} 1$ $\left.2 / \mathrm{m}, \mathrm{a}=18.84 \AA, \mathrm{b}=3.787 \AA, \mathrm{c}=12.326 \AA, \beta=102.67^{\circ}\right)$. As the distance from the inlet of the reactor increases, the intensity of the two peaks (010) and (020) becomes stronger, and other less intense peaks emerge corresponding to other 


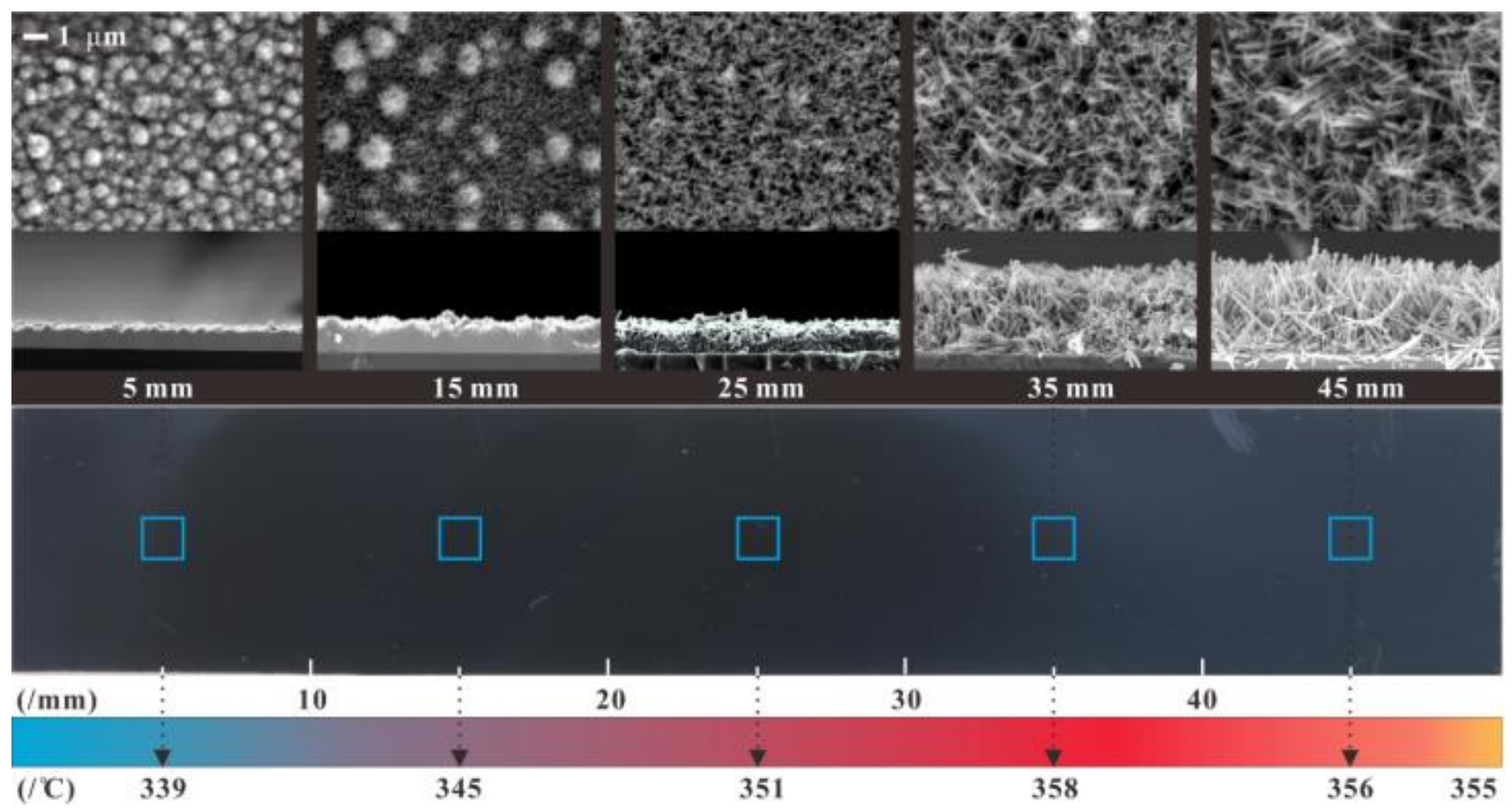

Figure 2

SEM images showing variation in morphology of $\mathrm{WO}_{\mathrm{x}}$ thin filmsshowing structures that vary from planar to NRs as a function of distance from the reactor inlet $(5,15,25,35,45 \mathrm{~mm})$ and the corresponding substrate surface temperature.

reflections of $\mathrm{W}_{17} \mathrm{O}_{47}\left(\mathrm{WO}_{2.77}\right)$. Reflections of the monoclinic $\mathrm{W}_{25} \mathrm{O}_{73}\left(\mathrm{WO}_{2.92}\right)$ structure (ICSD 01-071-0070, $\left.\mathrm{P} 12 / \mathrm{c}, \mathrm{a}=11.93 \AA, \mathrm{b}=3.82 \AA, \mathrm{c}=59.72 \AA, \beta=98.30^{\circ}\right)$ are also observed. Therefore the as-synthesized $\mathrm{WO}_{\mathrm{x}}$ thin film is comprised of $\mathrm{W}_{25} \mathrm{O}_{73}\left(\mathrm{WO}_{2.92}\right)$ and $\mathrm{W}_{17} \mathrm{O}_{47}\left(\mathrm{WO}_{2.77}\right)$. Moreover, the increase of relative intensity of diffraction peaks (010) and (020) with increasing distance from the inlet strongly suggests the growth direction of the NR was along [010], which correlates with SEM since the NR structure appears and the length of NRs increase as the distance from the inlet increases above $25 \mathrm{~mm}$ (Figure 2). However, the total intensity of each diffraction peak decreased between 25 and $45 \mathrm{~mm}$, where the length of NRs increases, possibly due to the decrease in NR occupied surface areabetween 25 and $45 \mathrm{~mm}$.

The X-ray photoelectron spectra in the $\mathrm{W} 4 \mathrm{f}$ region were obtained at points $45 \mathrm{~mm}$ and $5 \mathrm{~mm}$ from the inlet, where the NRs and planar structures were found respectively, and are shown in Figures $4 \mathrm{a}$ and $4 \mathrm{~b}$. By fitting the spectrum recorded at $45 \mathrm{~mm}$ (NRs structure), the main peaks (in red) at 36.0 and $38.1 \mathrm{eV}$ can be assigned to $\mathrm{W} 4 \mathrm{f}_{7 / 2}$ and $\mathrm{W}_{4} \mathrm{f}_{5 / 2}$ peaks of $\mathrm{W}^{6+}$ respectively[20]. The lower binding energy peaks (in blue) at 34.6 and $36.9 \mathrm{eV}$ correspond to $\mathrm{W}^{4+}$ [21]. The ratio of $\mathrm{W}^{6+}$ to $\mathrm{W}^{4+}$ was calculated via the ratio of areas of those peaks, which was $2.91 \pm 0.01$, e.g. $\mathrm{WO}_{2.92}$ at 45 $\mathrm{mm}$, and $2.85 \pm 0.01$, e.g. $\mathrm{WO}_{2.85}$ at $5 \mathrm{~mm}$. The XPS analysis, which only measures around a $10 \mathrm{~nm}$ depth of samples, suggests that the surface of the NRs at $45 \mathrm{~mm}$ are comprised of $\mathrm{WO}_{2.92}$ phase, agreeing with the XRD pattern at $45 \mathrm{~mm}$ where reflections of $\mathrm{WO}_{2.92}$ can be found. At
$5 \mathrm{~mm}$ XPS indicates $\mathrm{WO}_{2.85}$ as the surface phase, indicating the surface of the planar region appears less oxidised, possible due to relatively reduced surface area or relatively lower deposition temperature.

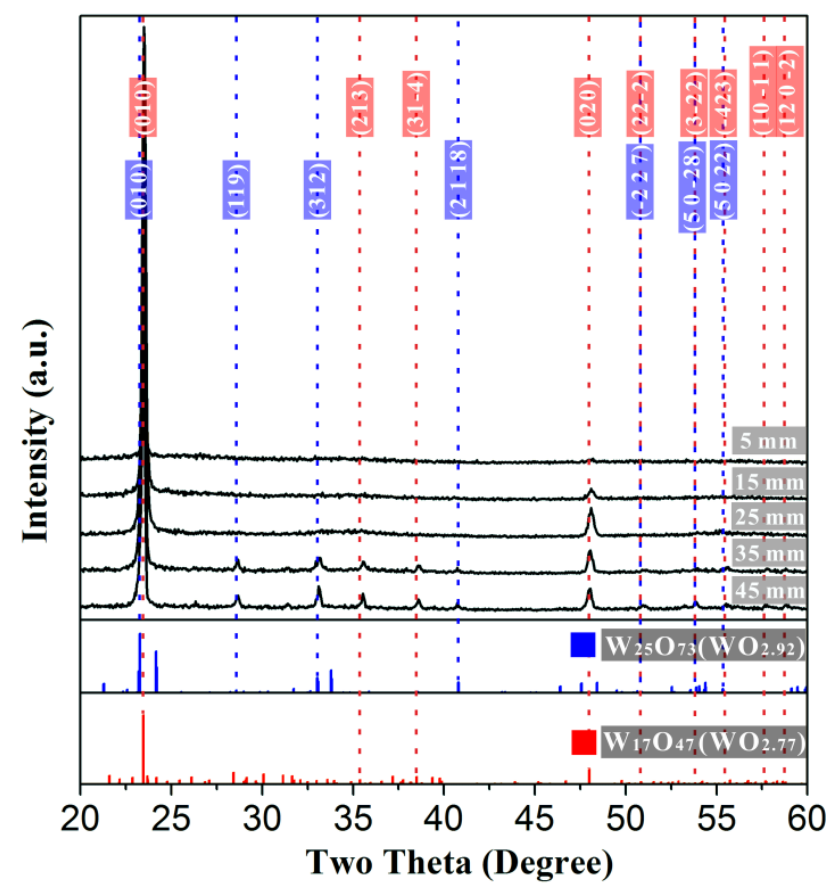

Figure 3 Glancing angle XRD patterns of various points within a $\mathrm{WO}_{\mathrm{X}}$ thin film deposited for $30 \mathrm{~min}$ at various distance $(5,10$, $15,25,35$ and $45 \mathrm{~mm}$ ) from the inlet of the reactor (with 
reference patterns for $\mathrm{W}_{17} \mathrm{O}_{47}\left(\mathrm{WO}_{2.77}\right)$ in red and $\mathrm{W}_{25} \mathrm{O}_{73}$ $\left(\mathrm{WO}_{2.92}\right)$ in blue).

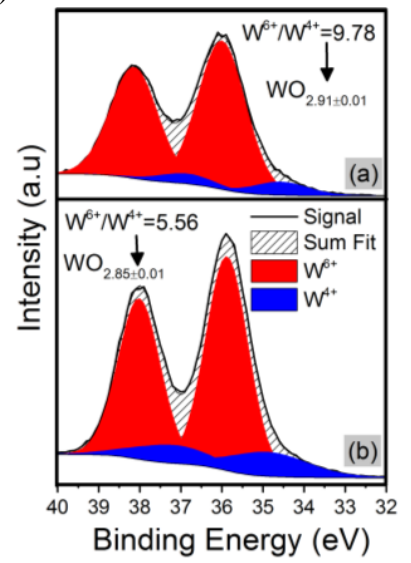

Figure $4 \mathrm{X}$-ray photoelectron spectra of $\mathrm{W} 4 \mathrm{f}$ region recorded at points (a) $45 \mathrm{~mm}$ and (b) $5 \mathrm{~mm}$ from the inlet with NRs and planar structure respectively. By fitting this spectrum, the oxidation states of $\mathrm{W}^{4+}$ (in blue) and $\mathrm{W}^{6+}$ (in red) were obtained.

STEM image of a single NR with length $4.9 \mu \mathrm{m}$ showed an increase in diameter from 20 to $150 \mathrm{~nm}$ along the growth direction (Figure 5a). In low magnification TEM as demonstrated in Figure 5c, the uniform NRs congregated together with smaller diameter at the bottom and longer at the top. Element linear scanning along a single NR (Figure 5a) shows the amount of tungsten and oxygen increase along the growth direction, however oxygen appears to increase less than tungsten i.e. $\mathrm{WO}_{\mathrm{x}}$ appears to become more oxygen deficient. This is possibly due to formation of crystallographic shear planes causing sub-stoichiometric planar defects [19]. The HRTEM image and corresponding Fast Fourier Transform (FFT) pattern (inset) in Figure 5b, which corresponds to the square-enclosed area in Figure 5a, revealed $d$-spacings along the growth direction of $0.37 \pm$ $0.01 \mathrm{~nm}$, which can be attributed to the (010) planes of monoclinic $\mathrm{WO}_{2.77}(0.378 \mathrm{~nm})$ or $\mathrm{WO}_{2.92}(0.382 \mathrm{~nm})$. It can be concluded that the growth direction of $\mathrm{WO}_{\mathrm{x}} \mathrm{NRs}$ was along the [010] direction. Streaks are observed in the FFT pattern (Figure 5b, inset) which were perpendicular to [010], which can be attributed to planar defects within the NRs caused by oxygen vacancies [22]. The presence of planar oxygen vacancies perpendicular to the growth direction [010] could suppress the growth along e.g. [100] and [001].

3.2 Growth modes of tungsten oxide thin films As shown in Figure 2, the as-synthesized $\mathrm{WO}_{\mathrm{x}}$ thin film structure changes from planar to NR on moving from the inlet to the outlet of the reactor. To understand how the various morphologies relate to the deposition conditions, the atomic processes of tungsten oxide thin film deposition by AACVD were considered (Figure 6). Six main steps occur: transportation of precursor onto the surface of the substrate, adsorption/desorption of precursor molecules on the substrate, pyrolysis of the precursor, tungsten atom diffusion, reaction for tungsten oxide/nucleation and finally thin film growth with three growth modes: FM (layer-by-layer) growth, SK (layer plus island) growth and VM (island) growth. To determine the competition amongst different growth modes, we considered the impact of various deposition conditions at each step.

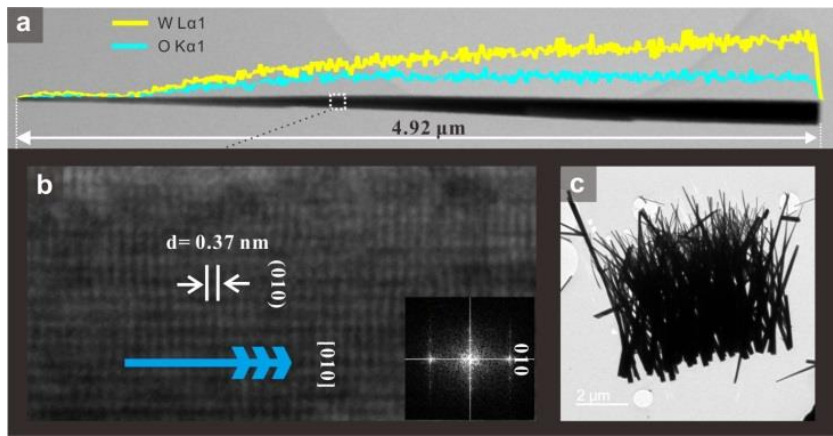

Figure 5 (a) STEM images of a single WOx NR with a length $4.92 \mu \mathrm{m}$ and the corresponding STEM-EDX elements linear scanning of tungsten and oxygen. (b) HRTEM image of selected section of NR and corresponding FFT pattern (inset). (c) TEM image in low magnification.

The precursor $\mathrm{W}(\mathrm{CO})_{6}$ was transported by carrier gas (such as $\mathrm{N}_{2}$ ) as a solution aerosol over the surface of a heated substrate at a rate $R_{\text {pre }}$ (in units of molecules $\mathrm{m}^{-2} \mathrm{~s}^{-1}$ ) which is

$$
R_{\text {pre }}=\frac{p}{\sqrt{2 \pi m k T}}
$$

where $p$ is precursor vapour pressure, $m$ is the molecular weight of precursor, $k$ is Boltzmann's constant and $T$ is the temperature of the vapour source (considered as the surface temperature of the substrate, $T_{s}$ ) [23]. If the flow of precursor aerosols is considered as an incompressible ideal fluid, and if gravity is ignored, $p$ can be estimated by a simplified form of Bernoulli's equation $p=\left(C_{\text {cons }}-\right.$ $\left.v_{w}^{2} / 2\right) \rho_{\text {pre }}$ where $\rho_{\text {pre }}$ is the density of precursor in the vapour (in units of molecules $\mathrm{m}^{-3}$ ), $C_{\text {cons }}$ is the constant of Bernoulli's equation and $v_{w}$ is flow speed (in unit of $\mathrm{m} \mathrm{s}^{-1}$ ) [24]. Hence, Equation 1 can be written as 


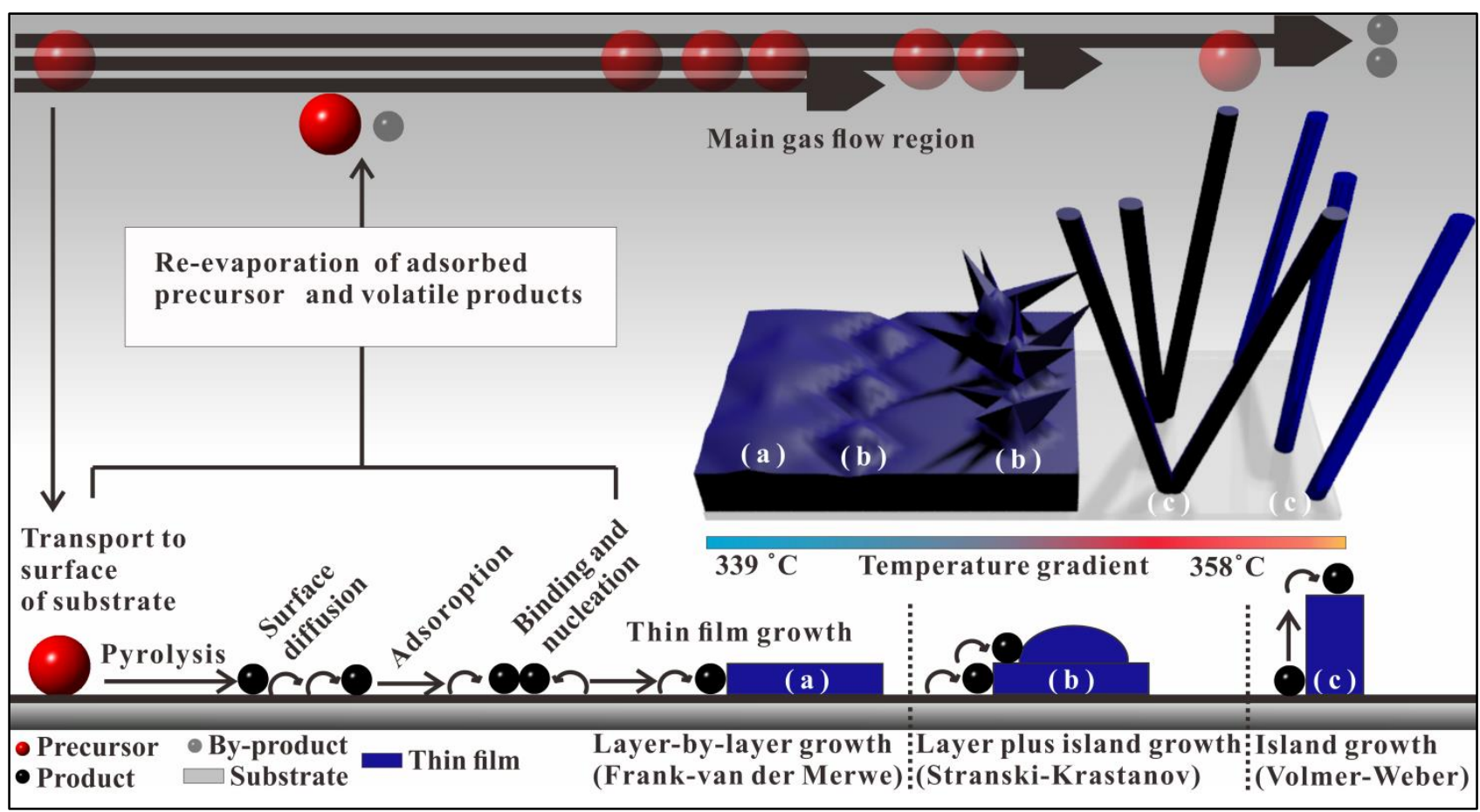

Figure 6 Typical atomistic processes during thin film growth via AACVD with three growth modes: (a) FM growth, (b) SK growth and (c) VM growth corresponding to various structures from planar to $\mathrm{NR}$ of $\mathrm{WO}_{\mathrm{x}}$.

$$
R_{\text {pre }}=\frac{\left(C_{\text {cons }}-\frac{1}{2} v_{w}^{2}\right) \rho_{\text {pre }}}{\sqrt{2 \pi m k T_{S}}}
$$

$\mathrm{W}(\mathrm{CO})_{6}$ molecules on the surface will only adsorb for a finite time before re-evaporation, which is described as the adsorption residence time $\tau_{a}$ :

$$
\tau_{a}=\frac{\exp \left(E_{a} / k T_{S}\right)}{v_{a}}
$$

where $E_{a}$ is the adsorption energy of $\mathrm{W}(\mathrm{CO})_{6}$ molecules on a quartz surface and $v_{a}$ is an absorption vibration frequency in the order of $1-10 \mathrm{THz}$ [23]. Hence the rate of mass transport $\left(R_{w}\right)$ of $\mathrm{W}(\mathrm{CO})_{6}$ onto the surface of the substrate before desorption can be expressed by

$$
R_{w}=R_{\text {pre }} \tau_{a}
$$

Subsequently, adsorbed $\mathrm{W}(\mathrm{CO})_{6}$ dissociates (above $250{ }^{\circ} \mathrm{C}$ ) forming tungsten atoms [25]. The rate of pyrolysis is controlled by the dissociation of the first $\mathrm{CO}$ after which the dissociation of the other five $\mathrm{CO}$ bonds is rapid [26]. Hence the pyrolysis of $\mathrm{W}(\mathrm{CO})_{6}$ is suggested to be a first order reaction, and the pyrolysis rate, $r_{\text {pre }}$ (in unit of atoms $\left.\mathrm{m}^{-2} \mathrm{~s}^{-1}\right)$ is $[16,27]$

$$
\begin{aligned}
n_{w} & =r_{\text {pre }}=R_{w}\left[A \exp \left(-E_{p} / R T_{s}\right)\right]^{i} \\
& =R_{\text {pre }} \tau_{a}\left[A \exp \left(-E_{p} / R T_{s}\right)\right]^{i}
\end{aligned}
$$

where $n_{w}$ is the density of the adatoms $\mathrm{W}$ (in unit of atoms $\mathrm{m}^{-2}$ ) condensed on the surface of the substrate, $R$ is the gas constant, $A$ is the pre-exponential and $E_{p}$ is the activation energy of $\mathrm{W}(\mathrm{CO})_{6}$ pyrolysis $(159$ to $192 \mathrm{~kJ} / \mathrm{mol})$ [28,29]. The temperature required for the maximum mass transport of $\mathrm{W}$ atoms is represented by $T^{*}$ which can be calculated by equation $T^{*}=E_{p}(R \ln A)^{-1}$; when $R_{w}=r_{p r e}$, and $E_{p}$ is $44.3 \mathrm{kcal} / \mathrm{mol}(185.5 \mathrm{~kJ} / \mathrm{mol}), \log A$ is $15.5(\ln A=36.7)$ and then $T^{*}$ is equal to $352{ }^{\circ} \mathrm{C}$ [26]. When $T_{s}$ is below $T^{*}, i$ $=1$, and the rate of reaction is limited by the pyrolysis rate of $\mathrm{W}(\mathrm{CO})_{6}$ on the substrate. If $T_{s}$ is above $T^{*}, i=0$, and the rate of reaction is limited by the rate at which $\mathrm{W}(\mathrm{CO})_{6}$ $\left(R_{w}\right)$ arrives at the substrate.

To estimate the $n_{w}$ and $\rho_{\text {pre }}$ at various positions of the surface of substrate, we assumed the as-synthesized $\mathrm{WO}_{\mathrm{x}}$ thin film only consists of the $\mathrm{WO}_{2.77}$ (ICSD 01-079-0171, P $\left.12 / \mathrm{m}, \mathrm{a}=18.84 \AA, \mathrm{b}=3.787 \AA, \mathrm{c}=12.326 \AA, \beta=102.67^{\circ}\right)$ phase, and the precursor $\mathrm{W}(\mathrm{CO})_{6}$ deposited equally on the walls of the reactor and on the surface of the substrate. Therefore, the adsorption energy $E_{a}$ is calculated as $1.2 \mathrm{eV}$ (115 kJ/mol), and profiles of $n_{w}$ and $n_{w}{ }^{2}$ against $T_{s}$ and $\rho_{\text {pre }}$ are shown in Figure 7. In Figure 7a and b, peak maxima $n_{w}$ and $n_{w}{ }^{2}$ appear at $\mathrm{T}_{\mathrm{s}}=\mathrm{T}^{*}=352{ }^{\circ} \mathrm{C}$ corresponding to the maximum mass transport of $\mathrm{W}$. Figure $7 \mathrm{c}$ shows that $\mathrm{n}_{\mathrm{w}}$ and $n_{w}{ }^{2}$ drop significantly above $25 \mathrm{~mm}$ from the inlet of the reactor, where $T_{s} \approx T^{*}=352{ }^{\circ} \mathrm{C}$.

The oxidation of $\mathrm{W}$ atoms occurs rapidly to nucleate $\mathrm{WO}_{\mathrm{x}}$ islands [30]. The sources of oxygen likely come from the solvent (acetone and/or methanol), or from air leaking 
into the reactor [31]. Consequently, the nucleation rate of tungsten oxide can be simplified to the nucleation rate of tungsten adatoms. If only re-evaporation and a perfect substrate surface are considered, and only single W adatoms can move, then the nucleation rate, $\mathrm{J}$, can be expressed by
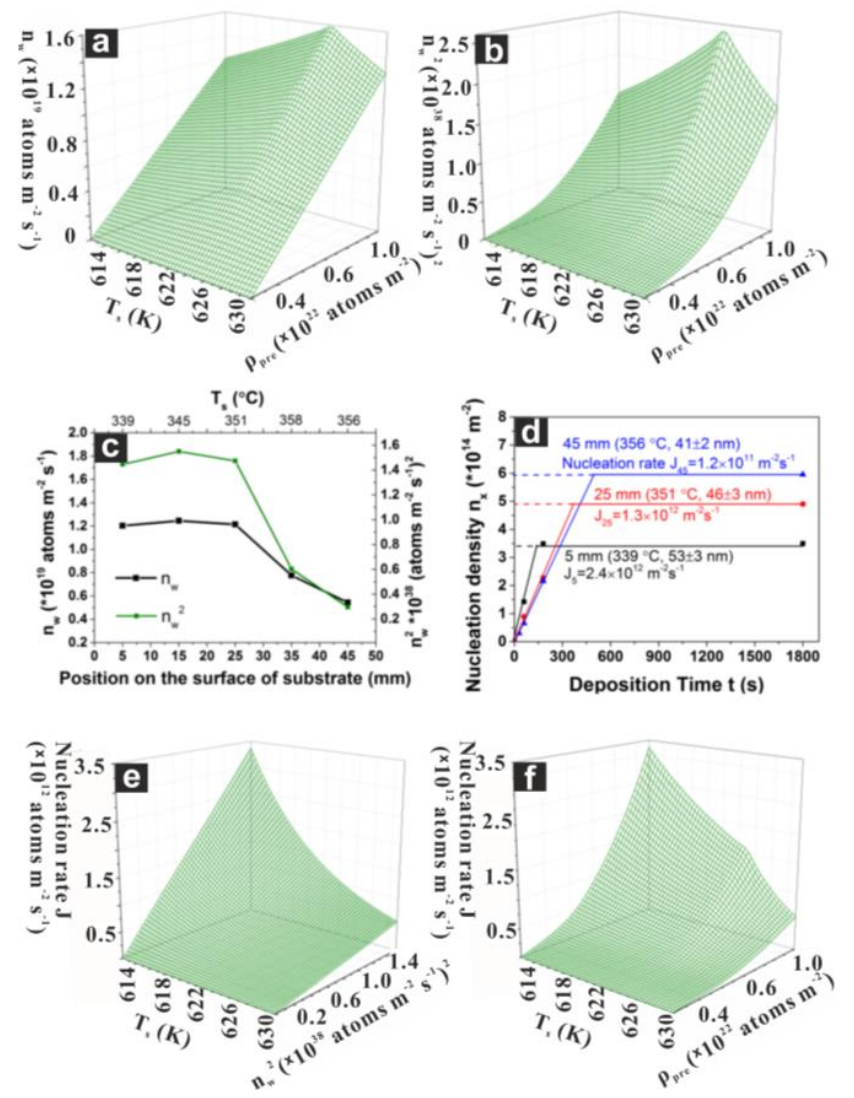

Figure 7 The scaled density profile of $\mathrm{W}$ atoms absorbed and deposited on the surface of the substrate before evaporation, $n_{w}$ and its square $n_{w}{ }^{2}$ for (a,b) temperature of substrate surface, $\mathrm{T}_{\mathrm{s}}$ $(612$ to $631 \mathrm{k})$ and the density of precursor aerosols, $\rho_{\text {pre }}(11.2$ to $\left.4.4 \times 10^{21} \mathrm{~m}^{-2}\right)$; (c) at various positions 5 to $45 \mathrm{~mm}$ from inlet of reactor; (d) Nucleation density $n_{x}$ and average size of nucleation islands (obtained from SEM images of $\mathrm{WO}_{\mathrm{x}}$ thin film deposited at 5,25 and $45 \mathrm{~mm}$ ) for 60,180 and 1800 seconds, with the calculation of nucleation rate $J$; The scaled profile of nucleation rate $J$ as a function of substrate temperature $T_{s}$ and square of W adatoms density, $n_{w}{ }^{2}$ (e), or precursor density $\rho_{\text {pre }}$ (f).

$$
\begin{aligned}
J & =\frac{d n_{x}}{d t}=\sigma D n_{w} n_{i}=n_{w}^{2} \sigma \frac{v_{d} a^{2}}{4} C \exp \left(\frac{E_{i}-E_{d}}{k T_{s}}\right) \\
& =\Omega \frac{\rho_{p r e}^{2}}{T_{s}} \exp \left(\frac{E_{a}+E_{i}-E_{d}-E_{p}^{i}}{k T_{s}}\right)
\end{aligned}
$$

where $n_{x}$ is the density of stable islands with size larger than critical nucleus size (smaller than which are unstable and decay) and $\sigma$ is a capture number representing the competition between islands for available adatoms [32].
The diffusion coefficient $D$ can be written by $0.25 v_{d} a^{2} \exp \left(-E_{d} / k T_{s}\right)$ where $E_{d}$ is the diffusion energy and $v_{d}$ the diffusion frequency (which smaller than $v_{a}$ ) and $\alpha$ is the jump distance which is of the same order as the surface repeat distance [16,23]. The $n_{i}$ is the density of critical nuclei on a perfect surface, which can be written by an atomistic expression as $C_{i} n_{w} \exp \left(E_{i} / k T_{s}\right)$ where $C_{i}$ is a statistical weight of order 1-10 [23]. The $\Omega$ is represented by $A^{i} C \sigma v_{d} a^{2}\left(4 v_{a}^{2}\right)^{-1}$. When $T_{s}>T^{*}\left(352{ }^{\circ} \mathrm{C}\right), \quad i=0$, otherwise $i=1$.

Figure $8 \mathrm{a}$ and $8 \mathrm{~b}$ show SEM images of a film at $5 \mathrm{~mm}$ deposited for 60 and 180 seconds respectively, showing spherical islands with average size $53 \pm 3 \mathrm{~nm}$, which occupied all available space on the substrate surface by 180 seconds. At $25 \mathrm{~mm}$ (Figure 8c and 8d), needles and spherical islands (average size $46 \pm 3 \mathrm{~nm}$ ) were found after 60 seconds deposition, and after 180 seconds the surface of the substrate was occupied by NRs. At $45 \mathrm{~mm}$, the density of NR islands was lower than $5 \mathrm{~mm}$ or $25 \mathrm{~mm}$ for the same deposition time (Figure 8e to $8 \mathrm{~g}$ ). After depositing for 1800 seconds, island coalescence can be seen when the film is viewed from the back, i.e. from the substrate side (Figure 8h). Abstracting from the SEM images, the plots of island density dependent on deposition time at different positions are shown in Figure $7 \mathrm{~d}$ in order to obtain a nucleation rate $J$ (unit of island $\mathrm{m}^{-2} \mathrm{~s}^{-1}$ ). The slopes of these plots show $J$ decreases along the distance from the inlet to the outlet of the reactors. Therefore, based on Equation 6, the plots of nucleation rate $J$ relating to the square of $\mathrm{W}$ adatoms density $n_{w}{ }^{2}$ and substrate temperature $T_{s}$ (Figure 7e), and relating to density of precursor $\rho_{\text {pre }}$ and $T_{s}$ (Figure 7f) shows that a high nucleation rate appears in regions of lower temperature and/or higher density of adatoms or precursor.

After nucleation, the island can grow along the direction perpendicular to the substrate, as shown in Figure 2 and Figure $8 \mathrm{c}$ to $8 \mathrm{f}$, with a growth rate $r_{\text {perp }}$ which was calculated by the thickness of thin film measured by crosssectional SEM (Figure 2). It depends on substrate temperature, as shown in Figure 9a where the Arrhenius plot gives an activation energy of $29.4 \pm 3.8 \mathrm{~kJ} / \mathrm{mol}$, slightly higher than previously reported, $0.22 \mathrm{eV}(21.2$ $\mathrm{kJ} / \mathrm{mol}$ ), from the precursor tungsten(IV) oxo fluoroalkoxide [33]. If nucleation is considered as thin film growth parallel to substrate, and the area each island can occupy is $d_{i}^{2}$, where $d_{i}$ is average diameter of an island assumed as a cube (volume $d_{i}^{3}$ ), then time $t_{i}$, which is represented by $1 /\left(J \times d_{i}^{2}\right)$, is the time taken by islands to occupy a unit $1 \mathrm{~m}^{2}$ area of the substrate surface, forming a thin film with thickness $d_{i}$. In other words, the nucleation of islands contributes to thin film perpendicular growth with thickness $d_{i}$ in the period of time $t_{i}$. Subsequently, the contribution of the nucleation rate $J$ to thin film perpendicular growth at rate $r_{i}$ is represented by $d_{i} / t_{i}=$ $J \times d_{i}^{3}$, and so $r_{i} \propto J$. 


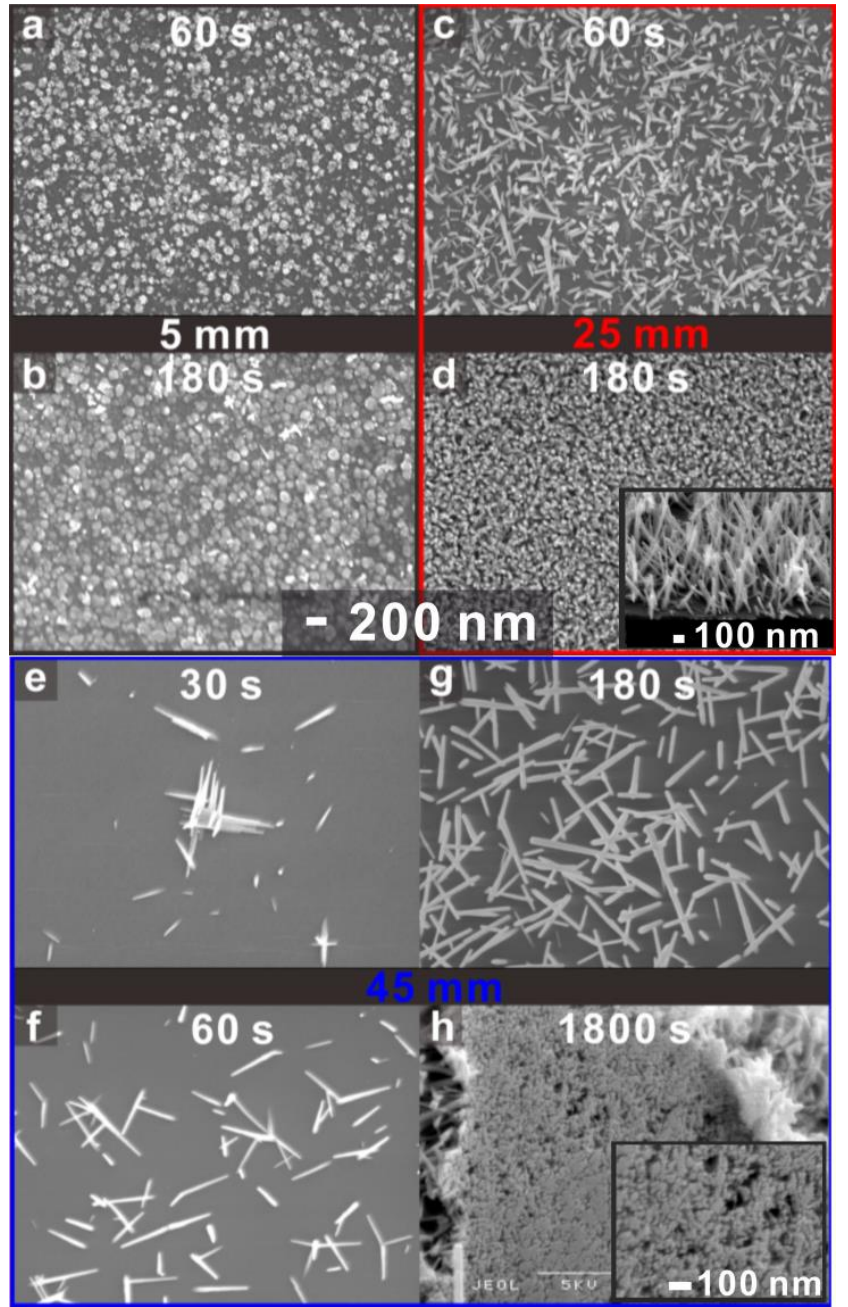

Figure 8 Determination of the number of nucleus of $\mathrm{WO}_{\mathrm{x}}$ thin film deposited by SEM for (a,b) 60 and 180 seconds at $5 \mathrm{~mm}$; (c,d) 60 and 180 seconds at $25 \mathrm{~mm}$ (higher magnification insect); $(\mathrm{e}, \mathrm{f}, \mathrm{g}) 30,60,180$ seconds at $45 \mathrm{~mm}$. (h) the back side of an assynthesized thin film at $45 \mathrm{~mm}$ delaminated from tje substrate (higher magnification insect).

At different positions on the surface of the substrate, the $r_{\text {perp }}$ and $J$ are different as shown in Figure 9b. Specifically, $r_{\text {perp }}$ increases and $J$ decreases from the inlet to the outlet, and in particular $r_{\text {perp }}$ experiences significant elevation above $25 \mathrm{~mm}$. Hence, various ratios of $r_{\text {perp }}$ to $J$, which can be represented by $r_{\text {perp }}$ to $r_{i}$, result in morphologies from planar to NR at different positions along the surface of the substrate (Figure 2). As shown in Figure 10, a wavelike surface of the as-synthesized thin films appears at positions $5 \mathrm{~mm}$ and $15 \mathrm{~mm}$, where the ratio of crest height to trough height is equal to the ratio of $r_{\text {perp }}$ and $r_{i}$. It is suggested that the presence of wave crests and troughs in these thin films is due to $r_{\text {perp }}$ being faster than $r_{i}$, and therefore after the first island has formed, the thin film starts to grow in a perpendicular direction to the island with rate $r_{\text {perp }}$ whilst other islands continue forming by nucleation with rate $J$, leading to varying thickness at different points. Therefore, as the ratio of $r_{\text {perp }}$ and $r_{i}$ increases, the height between the wave crests and troughs increases. At the limit (when that ratio reaches 7.1) NR structures emerge. As that ratio continues to increase, the NRs become longer and the density of NRs becomes lower, matching the observation by SEM at $35 \mathrm{~mm}$ and $45 \mathrm{~mm}$ (Figure 2 and 10).
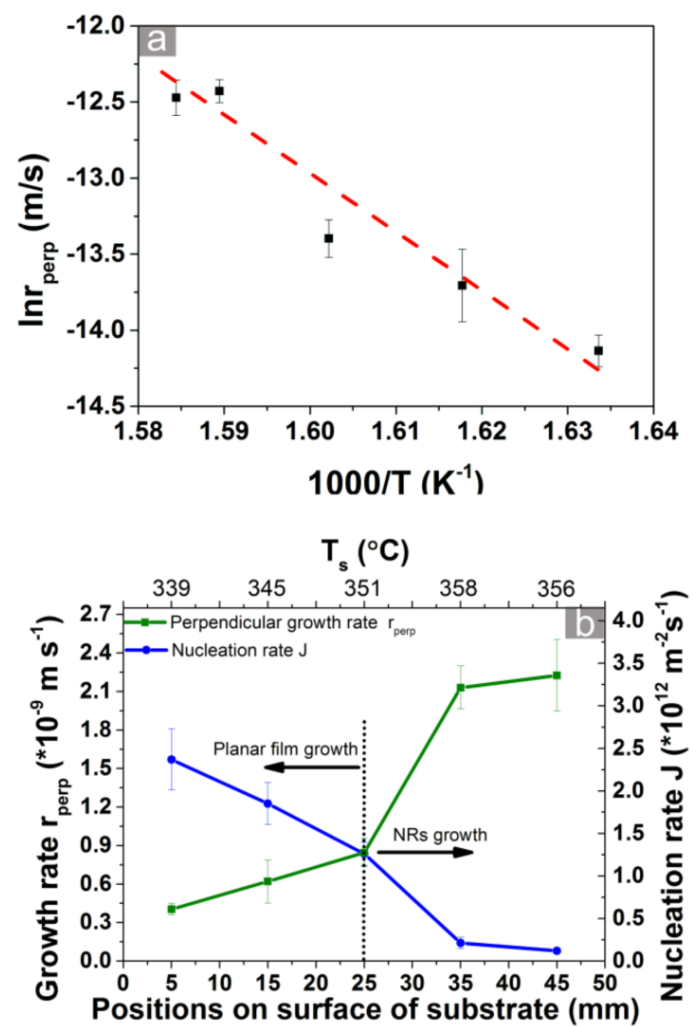

Figure 9 Arrhenius plot of growth rate along the direction perpendicular to substrate versus inverse temperature of substrate (a); the plot of growth rate $r_{\text {perp }}$ (green) and the nucleation rate $J$ (blue) at various positions from inlet to outlet of reactor (b). 


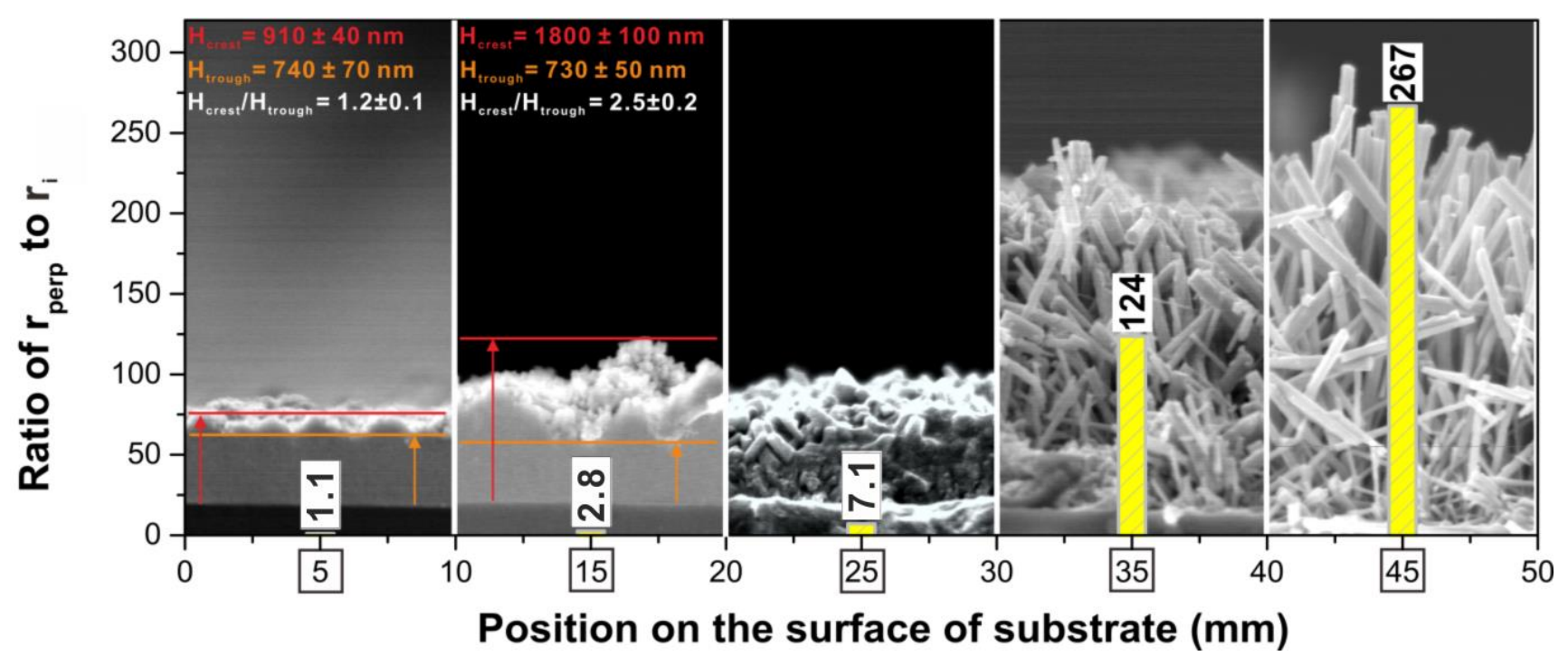

Figure 3 The increase of ratio of $r_{\text {perp }}$ and $r_{i}$ at position from 5 to $50 \mathrm{~mm}$ (yellow bar) resulting in the distance between the crest and trough larger. NR structure emerges after $25 \mathrm{~mm}$ with ratio above 7.1 .

4 Conclusions $\mathrm{WO}_{\mathrm{x}}$ thin films fabricated by AACVD shows two phases, $\mathrm{W}_{25} \mathrm{O}_{73}\left(\mathrm{WO}_{2.92}\right)$ and $\mathrm{W}_{17} \mathrm{O}_{47}\left(\mathrm{WO}_{2.77}\right)$. The morphologies change from planar to NR structure along the distance from the inlet to the outlet of the reactor due to the competition for adatoms on the substrate between perpendicular growth with rate $r_{\text {perp }}$ and nucleation (parallel growth) with rate $J$ resulting in various ratios of $r_{\text {perp }}$ to $r_{i}$ (film growth rate contributed by $J, r_{i} \propto$ $J)$. As that ratio increases the cross-section morphology of the surface of the planar as-synthesised thin film appears to be wave-like; when that ratio is larger than 7.1 the structure transitions to NR (Figure 10). The $r_{\text {perp }}$ is dependent on the substrate temperature $T_{s}$, and the $r_{i}$ is proportional to $J$, which is dependent on the density of precursor vapour $\rho_{\text {pre }}$ and $T_{s}\left(J\right.$ is proportional to $\rho_{\text {pre }}{ }^{2}$ and $T_{s}^{-1}$ ) (Equation 6). As the distance from the inlet to the outlet of the reactor increases, the change of deposition conditions of $T_{s}$ (increase) and $\rho_{\text {pre }}$ (decrease) results in $r_{\text {perp }}$ (increase) and $r_{i}$ (decrease), and an increase in the ratio of $r_{\text {perp }}$ to $r_{i}$ leading to a transition in growth mode from Frank van-der-Merwe (FM) (layer-by-layer) and StranskiKrastanov (SK) (layer plus island) to Volmer-Weber (VM) (island), and hence the morphology from planar to NR. Therefore, if the planar structure is desired the preferred deposition conditions are relatively low $T_{s}$ for compressing perpendicular growth, and high $\rho_{\text {pre }}$ for accelerating the nucleation rate $J$ (parallel growth). For NR structure, not only does the nucleation growth rate need to be compressed (relatively low $\rho_{\text {pre }}$ ), but the most important factor is an increase in $r_{\text {perp }}$ which is dependent on $T_{s}$ and activation energy $E_{a c t}$. In other words, when $E_{a c t}$ is high an extremely high $T_{s}$ would be required to obtain NR structure. Consequently, several methods and mechanisms have been introduced to decrease $E_{a c t}$ in order to fabricate NR structures at relatively low temperatures, i.e. VLS and VS mechanisms introduce catalysts to reduce $E_{a c t}$ for NR growth [34,35], the use of plasma can reduce $E_{a c t}$ [36], use of different precursors can also impact on the $E_{a c t}$ such as $\mathrm{W}(\mathrm{CO})_{6}\left(E_{\text {act }}=29.4 \mathrm{~kJ} / \mathrm{mol}\right), \mathrm{WO}\left[\mathrm{OCCH}_{3}\left(\mathrm{CF}_{3}\right)_{2}\right]_{4}(21.2$ $\mathrm{kJ} / \mathrm{mol}$, NR appear at around $300{ }^{\circ} \mathrm{C}$ ) and $\mathrm{WO}\left[\mathrm{OC}\left(\mathrm{CH}_{3}\right)_{2} \mathrm{CF}_{3}\right]_{4}(32.8 \mathrm{~kJ} / \mathrm{mol}, \mathrm{NR}$ appear at around $350{ }^{\circ} \mathrm{C}$ ) resulting in the required $T_{s}$ for $\mathrm{NR}$ structure increasing as $E_{a c t}$ increases.

Acknowledgements We gratefully acknowledge Dr. Robert Palgrave for his valuable and constructive suggestions.

\section{References}

[1] C.G. Granqvist, Sol. Energy Mater. Sol. Cells 60,201 (2000).

[2] M.-T. Chang, L.-J. Chou, Y.-L. Chueh, Y.-C. Lee, C.-H. Hsieh, C.-D. Chen, Y.-W. Lan, L.-J. Chen, Small 3,658 (2007).

[3] B.B. Sensors and Actuators, David G, M. Shtein, R.D. Wilson, S.L. Soled, E. Iglesia, J. Phys.Chem. B 103,630 (1999).

[4] W.B. Cross, I.P. Parkin, Chem. Commun. DOI 10.1039/B303800A1696 (2003).

[5] F. Di Maggio, M. Ling, A. Tsang, J. Covington, J. Saffell, C. Blackman, J. Sens. Sens. Syst. 3, (2014).

[6] S. Vallejos, P. Umek, T. Stoycheva, F. Annanouch, E. Llobet, X. Correig, P. De Marco, C. Bittencourt, C. Blackman, Adv. Funct. Mater. 23,1313 (2013).

[7] R. Liu, Y. Lin, L.Y. Chou, S.W. Sheehan, W. He, F. Zhang, H.J. Hou, D. Wang, Angew. Chem. 123,519 (2011).

[8] J. Su, X. Feng, J.D. Sloppy, L. Guo, C.A. Grimes, Nano Lett. 11,203 (2010).

[9] Z.-G. Zhao, M. Miyauchi, J. Phys.Chem. C 113,6539 (2009).

[10] M. Yaacob, M. Breedon, K. Kalantar-Zadeh, W. Wlodarski, Sens. Actuators, B 137,115 (2009). 
[11] C.S. Blackman, I.P. Parkin, Chem. Mater. 17,1583 (2005).

[12] X. Hou, K.L. Choy, Chem. Vap. Deposition 12,583 (2006).

[13] W.B. Cross, I.P. Parkin, S.A. O'Neill, P.A. Williams, M.F. Mahon, K.C. Molloy, Chem. Mater. 15,2786 (2003).

[14] S. Ashraf, C.S. Blackman, R.G. Palgrave, S.C. Naisbitt, I.P. Parkin, J. Mater. Chem. 17,3708 (2007).

[15]S. Vallejos, P. Umek, C. Blackman, J. Nanosci. Nanotechnol. 11,8214 (2011).

[16] J. Venables, G. Spiller, M. Hanbucken, Rep. Prog. Phys. 47,399 (1984).

[17] Y. Kojima, K. Kasuya, K. Nagato, T. Hamaguchi, M. Nakao, J. Vac. Sci. Technol., B 26,1942 (2008).

[18] F. Liu, L. Li, F. Mo, J. Chen, S. Deng, N. Xu, Cryst. Growth Des. 10,5193 (2010).

[19] A.M. Smith, M.G. Kast, B.A. Nail, S. Aloni, S.W. Boettcher, J. Mater. Chem. A 2,6121 (2014).

[20] V.I. Nefedov, Y.V. Salyn, G. Leonhardt, R. Scheibe, J. Electron. Spectrosc. Relat. Phenom. 10,121 (1977).

[21] P. Biloen, G.T. Pott, J. Catal. 30,169 (1973).

[22] J. Zhou, Y. Ding, S.Z. Deng, L. Gong, N.S. Xu, Z.L. Wang, Adv. Mater. 17,2107 (2005).

[23] J.A. Venables, Surf. Sci. 299,798 (1994).

[24] L.J. Clancy, Aerodynamics (Halsted Press,New York, 1975).

[25] A.A. Zinn, The Chemistry of Metal CVD105 (1994).

[26] K.E. Lewis, D.M. Golden, G.P. Smith, J. Am. Chem. Soc. 106,3905 (1984).

[27] J. Bloem, J. Cryst. Growth 50,581 (1980).

[28] W.-C.J. Wei, M.-H. Lo, Appl. Organomet. Chem. 12,201 (1998).

[29] T. Ziegler, V. Tschinke, C. Ursenbach, J. Am. Chem. Soc. 109,4825 (1987).

[30] S. Xu, L. Diao, J. Vac. Sci. Technol. A 26,360 (2008).

[31] A.M. Smith, M.G. Kast, B.A. Nail, S. Aloni, S.W. Boettcher, J. Mater. Chem. A 2,6121 (2014).

[32] F. Gibou, C. Ratsch, R. Caflisch, Phys. Rev. B 67,155403 (2003).

[33] H. Kim, R.O. Bonsu, C. O'Donohue, R.Y. Korotkov, L. McElwee-White, T.J. Anderson, ACS Appl. Mater. Interfaces (2015).

[34] R.S. Wagner, W.C. Ellis, Appl. Phys. Lett. 4,89 (1964).

[35] D. Sun, S. Senz, D. Hesse, J. Eur. Ceram. Soc. 24,2453 (2004).

[36] Q. Simon, D. Barreca, A. Gasparotto, C. Maccato, T. Montini, V. Gombac, P. Fornasiero, O.I. Lebedev, S. Turner, G. Van Tendeloo, J. Mater. Chem. 22,11739 (2012). 